\title{
Equestrian expertise affecting physical fitness, body compositions, lactate, heart rate and calorie consumption of elite horse riding players
}

\author{
Bong-Ju Sung' ${ }^{1}$, Sang-Yong Jeon ${ }^{3}$, Sung-Ro Lim³ ${ }^{3}$ Kyu-Eon Lee ${ }^{3}$, Hyunseok Jee ${ }^{2 * *}$ \\ 'Department of Sport Science, Korea Institute of Sport Science, Seoul, Korea \\ 2Department of Rehabilitation Medicine, Seoul National University Bundang Hospital, Seongnam, Korea \\ ${ }^{3}$ Korea Racing Authority, Gwacheon, Korea
}

Horse riding (HR) is a sport harmonized with rider and horse. HR is renowned as an effective sport for young and old women and men. There is rare study regarding comparison between elite horse riders and amateurs. We aimed to investigate comprehensive ranges of parameters such as change of lactate, heart rate, calorie, $\mathrm{VO}_{2} \mathrm{max}$, skeletal muscle mass, body water, body fat, etc between amateurs and professionals to emphasize HR not only as a sport training but also as a therapeutic aspect. We performed 3 experiments for comparing physical fitness, body compositions, lactate value, heart rate and calorie consumption change before and after riding between amateurs and elites. Around $3 \mathrm{yr}$ riding experienced elites are preeminent at balance capability compared to 1 yr riding experienced amateurs. During $18 \mathrm{~min}$ horse riding, skeletal muscle mass and body fat were interestingly increased and decreased, respectively. Lactate response was more sensitive in elites rather than amateurs and its recovery was reversely reacted. Exercise intensity estimated from heart rate was significantly higher in elites $(P<0.05)$. The similar pattern of calorie consumption during riding between amateurs and elites was shown. Horse riding possibly induces various physiological (muscle strength, balance, oxidative capability, flexibility, and metabolic control) changes within body and is thus highly recommended as combined exercise for women, children, and aged as therapeutic and leisure sport activity.

Keywords: Horse riding, Physical fitness, Elite player, Body compositions, Rehabilitation

\section{INTRODUCTION}

Horse riding (HR) is a particular sport activity that requires to be harmonized between rider and horse. This physical activity is also considered as an effective intervention to improve postural control balance preventive for falling (Kim and Lee, 2015; Sherrington et al., 2004). HR is categorized as therapeutic rehabilitation exercise and training physical fitness exercise. Riders exchange signals with horses by giving those to various parts of horses for controlling orientation and speed.

Riders control the movement of the horse by maintaining equilibrium between hands to upper-forearm of riders and reins-bit. Riding requires rhythmically continuous physical movement

with horse. High muscle strength of hands to upper-forearm and back-strength are ameliorated by horse riding. HR is quite efficient exercise for whole body because lower body strength is also highly required to adhere to horse while riding.

Heine (1997) reported that horse rider can have therapeutic benefits from the aspect of walk and postural balance reaction by means of rotation, up-down and left-right movement of riders through harmonized pelvic movement pattern with horse walking (Heine, 1997). Many studies reported that horse walking is similar to human pelvic movement while changing of horse walking speed and orientation stimulate rider's balance reaction (Murphy, 2008).

Liptak (2005) reported that balance reaction of head to body

${ }^{*}$ Corresponding author: Hyunseok Jee

Department of Rehabilitation Medicine, Seoul National University Bundang Hospital, 82 Gumi-ro 173beon-gil, Bundang-gu, Seongnam 463-707, Korea Tel: +82-31-787-8142, Fax: +82-31-787-4056, E-mail: jeenina2009@gmail.com Received: May 20, 2015 / Accepted: June 9, 2015 
control is ameliorated by HR (Liptak, 2005). Therapeutic benefits to medical regeneration by horse riding are also raised because improving not only physical traits such as muscle strength, agility, weight sustainability, coordinability between organs, but also mental, emotional, cognitive traits such as self-confidence, sensor coordination, spatial sense, etc are obtained by HR. HR causes rhythmical and repetitive movement and this improves blood circulation and muscle strain of the rider.

Riding is an aerobic exercise because horse riders have the similar respiratory capacity compared to soccer player. Lee et al. (2014) reported that indoor horse riding apparatus improves women's muscle strength, muscle endurance, balance, flexibility and remarkably femur muscle strength and its endurance (Lee et al., 2014).

HR consumes quite a lot of energy and reaches about $75 \%$ of maximal oxygen consumption during Jumping (Devienne and Guezennec, 2000). HR also raises 40-80\% of maximal metabolic rate (Westerling, 1983) and shows 136-188 heartbeat/min (Trowbridge et al., 1995). About 2.5 to 6.5 times of metabolic rate for riders is usually increased while the horse continues walking to trotting (Ainsworth et al., 1993).

As reported in previous reports, various physical changes by consuming remarkable energy would be caused with $90 \mathrm{sec}$ of acute riding. However, there are quite rare reports regarding the effect of HR from various aspects. Thus, we aimed to investigate comprehensive ranges of parameters such as change of lactate, heart rate, calorie, $\mathrm{VO}_{2} \mathrm{max}$, skeletal muscle mass, body water, body fat, etc between amateurs and professionals to emphasize HR not only as a sports training but also as a therapeutic aspect.

\section{MATERIALS AND METHODS}

\section{Subjects recruitments}

We recruited each of 6-7 for amateur and elite horse male riders experiencing range from 1 to $23 \mathrm{yr}$ (Table 1). Age variances are from about 20-37 yr old. We performed 3 experiments for com- paring physical fitness, body compositions, lactate value, heart rate and calorie consumption change before and after HR between amateurs and elites.

\section{Physical fitness parameters and those measurements}

We designed the experiment 1 for obtaining physical fitness data to compare between amateur and elite riders. The physical fitness consists of left and right grip strength, back strength, push-up, sit-up, trunk forward flexion, side step, standing on one leg with eyes closed, $\mathrm{VO}_{2} \max (\mathrm{mL} / \mathrm{kg} / \mathrm{min})$, and shuttle-run. These parameters are for comparing muscle strength, muscle endurance, cardiac capability, agility, balance, and flexibility of amateurs and elites. Each subject tried 2 times for both grip strength. Better value for back strength was obtained followed by 2 trials. Trunk forward flexion (T.K.K. 5103, Takei Co., Japan) was measured as $0.1 \mathrm{~cm}$ unit and standing on one leg with eyes closed was tried with 0.1 sec unit.

\section{Body compositions and lactate values}

Body compositions (AVIS 333 PLUS, Jawon Medical, Korea), such as body weight, body water, skeletal muscle mass, body fat

Table 2. Physical fitness comparison between Amateur and Elite riders

\begin{tabular}{lcc}
\hline & Amateur riders & Elite riders \\
\hline Grip strength (Right) (kg) & $42.71 \pm 6.01$ & $48.94 \pm 3.07$ \\
Grip strength (Left) (kg) & $45.40 \pm 7.64$ & $48.31 \pm 4.97$ \\
Back strength (kg) & $112.43 \pm 21.79$ & $136.57 \pm 21.10$ \\
Push-up (beat/min) & $33.57 \pm 12.45$ & $40.00 \pm 11.11$ \\
Sit-up (beat/min) & $38.86 \pm 10.90$ & $45.14 \pm 13.28$ \\
Sit and reach (cm) & $12.09 \pm 10.17$ & $19.31 \pm 10.14$ \\
Side step (beat/20 sec) & $38.14 \pm 3.13$ & $38.71 \pm 5.09$ \\
Standing on one leg with & $27.74 \pm 16.01$ & $58.29 \pm 27.54$ \\
$\quad$ eyes closed (sec) & & \\
V0 2 max (mL/kg/min) & $46.68 \pm 9.78$ & $50.64 \pm 8.15$ \\
20 m shuttle-run (beat) & $52.40 \pm 20.18$ & $48.71 \pm 10.21$ \\
\hline
\end{tabular}

$n=6$, Values are means \pm standard deviation (S.D.).

Table 1. Ages, height, weight and riding experiences of subjects

\begin{tabular}{lllllc}
\hline & & Ages $(\mathrm{yr})$ & Height $(\mathrm{cm})$ & Weight $(\mathrm{kg})$ & Experiences $(\mathrm{yr})$ \\
\hline Amateur riders & Experiment 1 & $24.57 \pm 7.44$ & $176.00 \pm 4.93$ & $68.14 \pm 7.56$ & $1.00 \pm 0.00$ \\
& Experiment 2 & $20.67 \pm 2.42$ & $175.50 \pm 8.17$ & $68.63 \pm 15.62$ & $4.83 \pm 2.93$ \\
Elite riders & Experiment 3 & $25.67 \pm 7.53$ & $171.17 \pm 4.83$ & $62.65 \pm 7.48$ & $10.50 \pm 11.34$ \\
& Experiment 1 & $20.29 \pm 0.49$ & $172.29 \pm 3.86$ & $66.71 \pm 9.53$ & $3.14 \pm 2.34$ \\
& Experiment 2 & $37.33 \pm 4.41$ & $173.17 \pm 5.49$ & $71.15 \pm 8.55$ & $23.17 \pm 8.18$ \\
& Experiment 3 & $32.17 \pm 10.82$ & $175.17 \pm 6.97$ & $73.70 \pm 8.79$ & $15.83 \pm 11.20$ \\
\hline
\end{tabular}

$n=6-7$, Values are means \pm standard deviation (S.D.). 
were measured before and after HR (Table 3). Lactate was analyzed (Biosen c-line, EKF Diagnostics, Germany) at rest, just before riding, on peak of exercise, and 5, 15 and 30 min of post-HR. Recovery of lactate rate is obtained from below formulation (Fig. 3).

Recovery rate of lactate $=\{$ (lactate value at all out-lactate value at measured time after $\mathrm{HR}$ )/(lactate value at all out-lactate value at rest) $\} \times 100$

\section{Heart rate and calorie consumption}

Heart rate (Polar F1 heart rate monitor, Pola Electro, Finland) (Table 4) and calorie consumption (Cosmed Quark b2, COSMED, Italy) (Fig. 4) were measured during Show Jumping which consists of a course including 3 min rest, 2 min walk, 5 min fast, 3 min walk, jump, and recovery. Exercise intensity was assumed as a ratio of heart rate to maximum heart rate (Fig. 2).

\section{Statistical analysis}

All data were described as mean \pm standard deviation (S.D.). Each parameter group between amateur and elite groups was compared by Mann Whitney test. We also obtained values for Table 3 and Table 4 by using below formula 1 to offset the age gap between amateurs and elite riders and those obtained values were compared by paired t-test. SPSS Version 18.0 was used for whole statistical analysis. The statistical significance level was set at $P<0.05, P<0.01$ and showed the exact value for all analysis.

Formula 1: (value obtained after riding-value obtained before riding)/value obtained after riding

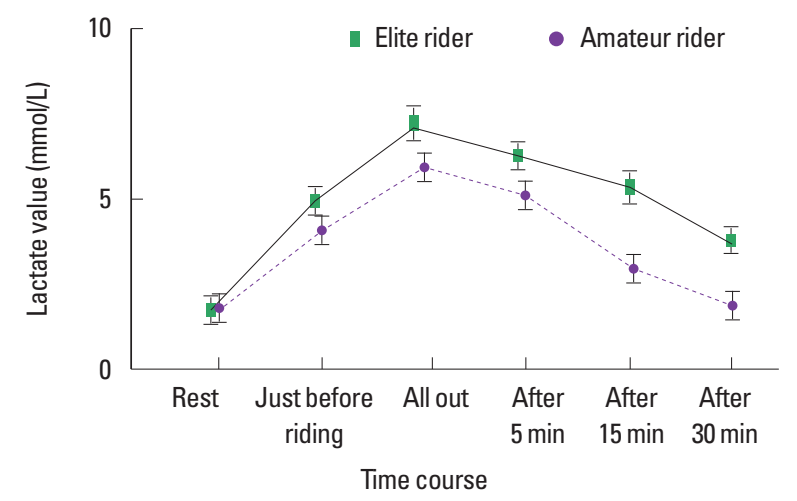

Fig. 1. Comparison of lactate level ( $\mathrm{mmol} / \mathrm{L}$ ) according to time course between amateur and elite horse riders. Lactate level was measured during and after Show Jumping: rest, just before riding, all out, after $5 \mathrm{~min}$, after $15 \mathrm{~min}$, after $30 \mathrm{~min}$. There was no statistical difference during the measurement. Amateur average values were $9.6 \%$ higher than elites, however, Elite values of lactate were higher compared to amateur values in the whole period of Show Jumping afterward. The data was shown as mean \pm standard deviation (S.D.)

\section{RESULTS}

\section{Characteristics of subjects in each experiment}

We compared physical fitness, body compositions, heart rate, calories consumption, lactate values between amateurs and elite riders by series of 3 experiments.

In experiment 1 (Table 1), ages of amateur and elite riders are $24.57 \pm 7.44$ and $20.29 \pm 0.49$, respectively. Heights are $176.00 \pm$ $4.93(\mathrm{~cm})$ for amateurs and $172.29 \pm 3.86(\mathrm{~cm})$ for elites. Weight differences between amateurs and elites are $68.14 \pm 7.56(\mathrm{~kg})$ and $66.71 \pm 9.53(\mathrm{~kg})$, respectively. Amateurs are $1 \mathrm{yr}$ experienced and elites are approximately $3.14 \pm 2.34 \mathrm{yr}$.

In experiment 2 (Table 1), amateurs are $20.67 \pm 2.42 \mathrm{yr}$ old and elites are $37.33 \pm 4.41 \mathrm{yr}$ old. Heights of amateurs are 175.50 \pm $8.18(\mathrm{~cm})$ and $173.17 \pm 5.49(\mathrm{~cm})$. Amateur weight $(\mathrm{kg})$ is $68.63 \pm$ 15.62 and elite weight is $71.15 \pm 8.55$. Amateurs have approximately 4.83 yr experiences and elites have about $23.17 \mathrm{yr} \mathrm{HR}$ experiences.

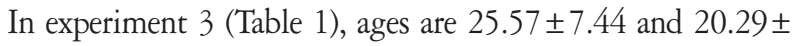
0.49 for amateurs and elites, respectively. Heights $(\mathrm{cm})$, weight $(\mathrm{kg})$, and experiences (year) of amateurs and elites are as follows; $171.17 \pm 4.83$ vs $175.17 \pm 6.97,62.65 \pm 7.48$ vs $73.70 \pm 8.79$, and $10.50 \pm 11.34$ vs $15.83 \pm 11.20$.

\section{Physical fitness parameters in experiment 1}

As physical fitness parameters, we compared both hands grip strength $(\mathrm{kg})$, back strength $(\mathrm{kg})$, push-up, sit-up, trunk forward

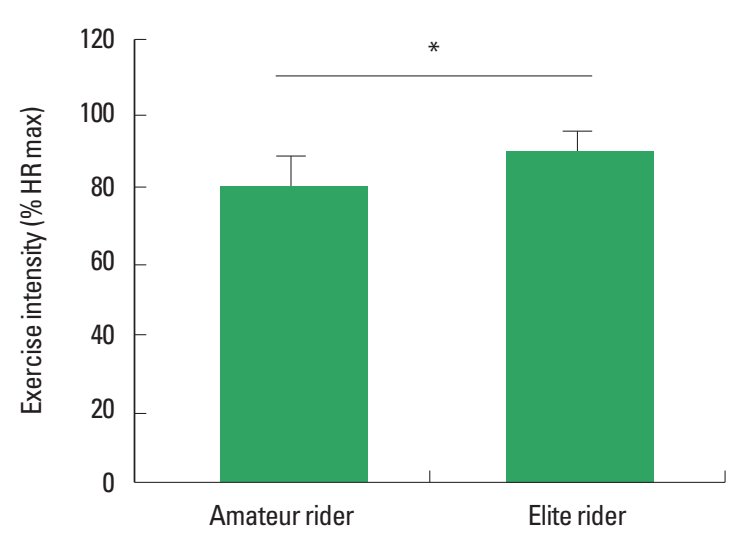

Fig. 2. Exercise intensity by \% of maximal heart rate. Exercise intensity during horse riding (HR) was pursued by calculating \% to maximal heart rate. Average heart rate of amateurs was about $82 \%$ and that of elites were about $89 \%$. Elite has significantly higher exercise intensity during HR compared to amateurs $(P=0.037)$. Data were described as mean \pm standard deviation (S.D). 
Table 3. Change of weight, body water, skeletal muscle mass, and body fat between Amateur and Elite riders after riding

\begin{tabular}{llcc}
\hline & & Amateur riders & Elite riders \\
\hline Body weight $(\mathrm{kg})$ & Before & $68.63 \pm 15.62$ & $71.15 \pm 8.55$ \\
& After & $68.52 \pm 15.64$ & $71.02 \pm 5.54$ \\
& Value, (after-before)/after & $-0.002 \pm 0.003$ & $-0.002 \pm 0.003$ \\
Body water $(\mathrm{kg})$ & Before & $41.82 \pm 7.67$ & $41.82 \pm 4.62$ \\
& After & $42.27 \pm 7.39$ & $42.38 \pm 4.59$ \\
Skeletal muscle mass $(\mathrm{kg})$ & Value, (after-before)/after & $0.012 \pm 0.016$ & $0.014 \pm 0.010$ \\
& Before & $32.23 \pm 6.25$ & $32.33 \pm 3.97$ \\
Body fat $(\%)$ & Valuer (after-before)/after & $32.52 \pm 6.01$ & $32.80 \pm 3.94$ \\
& Before & $0.010 \pm 0.016$ & $0.014 \pm 0.011$ \\
& After & $11.57 \pm 5.58$ & $14.08 \pm 3.84$ \\
& Value, (after-before)/after & $10.97 \pm 5.95$ & $13.25 \pm 3.49$ \\
\hline
\end{tabular}

$\mathrm{n}=6$, Values are means \pm standard deviation (S.D.)

Table 4. Change of average heart rate between Amateur and Elite riders

\begin{tabular}{|c|c|c|c|}
\hline & & Amateur riders & Elite riders \\
\hline Rest 3 min (beat/min) & & $94.83 \pm 12.83$ & $\begin{array}{c}81.43 \pm 6.17^{*} \\
(P=0.037)\end{array}$ \\
\hline Walk 2 min (beat/min) & Value, (after-before)/after & $\begin{array}{r}121.67 \pm 13.11 \\
0.22 \pm 0.03\end{array}$ & $\begin{array}{c}92.90 \pm 11.91^{*} \\
(P=0.021) \\
0.14 \pm 0.09\end{array}$ \\
\hline Fast 5 min and Walk 3 min (beat/min) & Value, (after-before)/after & $\begin{array}{c}149.82 \pm 19.20 \\
0.23 \pm 0.06\end{array}$ & $\begin{array}{c}128.87 \pm 16.22 \\
0.22 \pm 0.06\end{array}$ \\
\hline Jump (practice) (beat/min) & Value, (after-before)/after & $\begin{array}{c}164.57 \pm 29.48 \\
0.08 \pm 0.09\end{array}$ & $\begin{array}{c}150.39 \pm 20.32 \\
0.14 \pm 0.03\end{array}$ \\
\hline Jump (beat/min) & Value, (after-before)/after & $\begin{array}{c}176.00 \pm 27.87 \\
0.07 \pm 0.04\end{array}$ & $\begin{array}{c}164.40 \pm 14.27 \\
0.09 \pm 0.05\end{array}$ \\
\hline Recovery (after $5 \mathrm{~min}$ ) (beat/min) & & $123.44 \pm 5.71$ & $\begin{array}{c}102.08 \pm 12.67^{* *} \\
(P<0.0001)\end{array}$ \\
\hline
\end{tabular}

$\mathrm{n}=6$. Values are means \pm standard deviation (S.D.).

${ }^{*} P<0.05$. ${ }^{*} P<0.01$, statistical significances between Amateur and Elite riders.

flexion ( $\mathrm{cm}$ ), side-step, standing on one leg with eyes closed (sec), $\mathrm{VO}_{2} \max (\mathrm{mL} / \mathrm{kg} / \mathrm{min})$, and shuttle-run of amateurs and elite riders (Table 2).

Right grip strength has $14.6 \%$ more in elites than amateur and left grip strength is $6.4 \%$ more in elites than amateurs. Elites in back strength are $21.5 \%$ more than amateurs. Whole values are better in elites than amateurs even though there was no statistical difference (Table 2). Interestingly, balance test examined by standing on one leg with eyes closed has almost 2 times more in elites.

\section{Body compositions and lactate level in amateurs vs elites}

We classified changes of weight, body water, skeletal muscle mass, and body fat as body compositions and those parameters are compared between amateurs and elites before and after HR (Table 3). Further, we analyzed lactate values and its recovery rate during and after riding (Fig. 1 and 3). Riding as exercise intensity was also measured by $\%$ of maximal heart rate (Fig. 2).

In Table 3, we just focused on the extent of change because one of big factors such as a difference of age between amateurs and elites can affect the body composition parameters (Table 1). We thus output the values of each parameter from the formula 1 described in Materials and Methods. There was no change of body weight between amateurs and elites before and after riding (Table 3). The change of body water was $16.7 \%$ greater in elites than amateurs after riding, however, there was no statistical difference. Skeletal muscle mass also increased in elites about $40 \%$ after riding even though there was no statistical difference. Both amateurs $(-0.086 \mathrm{~kg})$ and elites $(-0.061 \mathrm{~kg})$ were lost their body fat after ridings even though the statistical difference was not shown between the decreased values.

In lactate changes during riding (Fig. 1) and its recovery rate after riding (Fig. 3) between amateurs and elites, we could not 


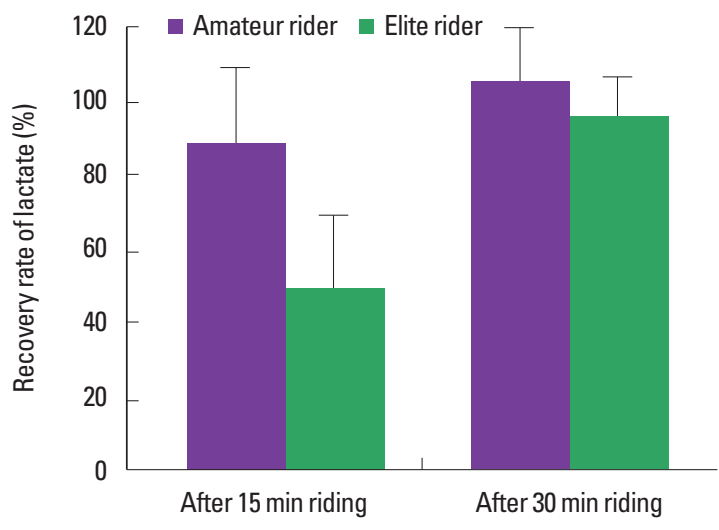

Fig. 3. The recovery of lactate values after $15 \mathrm{~min}$ and $30 \mathrm{~min}$ horse riding between amateurs and elites. The recovery of lactate level was higher in amateurs compared to elites in both $15 \mathrm{~min}$ and 30 min after horse riding (HR) However, there was no statistical difference. In 15 min later of $\mathrm{HR}$, the recovery rate of lactate was shown as $87 \%$ and $53 \%$ in amateurs and elites, respectively. Those were increased $114 \%$ and $91 \%$ in corresponding subjects after 30 min of HR. Data were described as mean \pm standard deviation (S.D).

find statistical difference. At rest state, lactate of amateurs is about 9.6\% more than that of elites. When HR started till finished, lactate of elites increased averagely $0.97 \mathrm{mmol} / \mathrm{L}$ more than that of amateurs (Fig. 1). Lactate recovery rate after 15 and 30 min riding shows that amateurs are more susceptible to lactate recovery. About $87 \%$ of recovery was shown in amateurs after $15 \mathrm{~min}$ of HR. Around $53 \%$ of recovery was shown in elites at the same time (Fig. 3). When 30 min passed after HR, 114\% and 91\% were shown recovery of amateurs and elites lactate values, respectively.

Exercise intensity was produced as the ratio of average heart rate to maximal heart rate during HR. Elites and amateurs of exercise intensity shows in Fig. 2. Amateur is almost $82 \%$ and elite is almost $89 \%$ compared to corresponding maximal heart rate $(P=0.037)$.

\section{Comparison of heart rates and calorie consumption between amateurs and elites:}

We obtained data regarding heart rates and calorie consumption from the course of Show Jumping described in Materials and Methods (Table 4) (Fig. 4).

At rest state, heart rate of elites is significantly lower than amateurs $(P=0.037)$. During 2 min walking, heart rate of elites was significantly lower than that of amateurs $(P=0.021)$. After $2 \mathrm{~min}$ walking, elite heart rate was lower than amateurs, however, there was no significant difference. Elite heart rate was lower than ama-

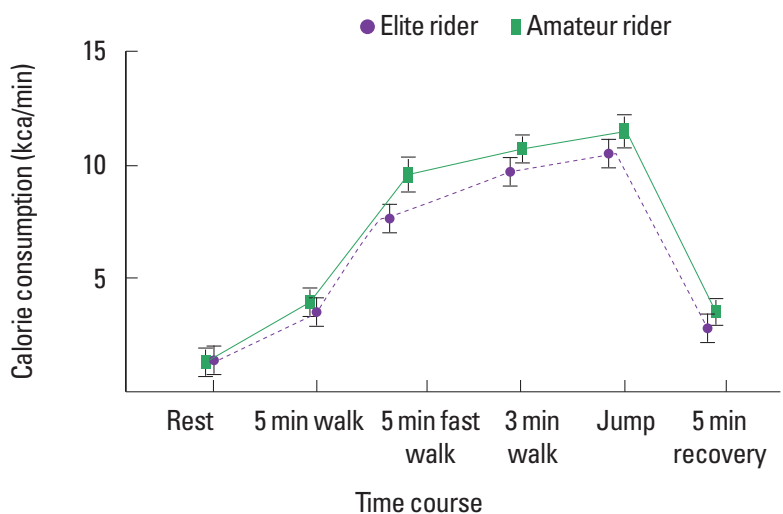

Fig. 4. Comparison of calorie consumption (kcal/min) during and after horse riding between amateurs and elites. During Show Jump that consists of rest, 2 min walk, 5 min fast walk, 3 min walk, jump, and 5 min recovery after horse riding $(\mathrm{HR})$, calorie consumption was measured. Average values of calorie consumption in amateurs were higher in whole periods of $\mathrm{HR}$ compared to elites. However, there was no statistical significance. As exercise intensity goes higher, calorie consumption was also increased. Data were described as mean \pm standard deviation (S.D)

teurs during whole period of $\mathrm{HR}$. After $5 \mathrm{~min}$ of $\mathrm{HR}$, the recovery of heart rate was faster in elites rather than amateurs $(P<0.01)$. In order to offset the difference of biological factors such as age, etc of subjects in experiment 3 described Table 1 between amateurs and elites, we also use the formula 1 shown in Materials and Methods. Increase range (value, [After-before]/after) of elites were only greater when the riders were at the $5 \mathrm{~min}$ Fast and the $3 \mathrm{~min}$ Walk to Jump (practice) and Jump (practice) to Jump (Table 4).

Regarding calorie consumption, averagely $0.84 \mathrm{kcal} / \mathrm{min}$ was more consumed in amateurs compared to elites during HR (Fig. 4). There was no statistical difference shown for calorie consumption.

\section{DISCUSSION}

We designed 3 different experiments to examine the positive effect of HR, which results in varing from 10 components of physical fitness 4 body compositions, lactate value, heart rate, and calorie consumption. These data were obtained before and after HR between amateurs and elites. Around 3 yr riding experienced elites are preeminent at balance capability compared to $1 \mathrm{yr}$ riding experienced amateurs even though there was no statistical significance. During 18 min HR, it did not suggest that statistical difference would be shown between body compositions, however, skeletal muscle mass and body fat were interestingly increased and decreased, respectively (Table 3). Coincidently, lactate re- 
sponse was more sensitive in elites rather than amateurs (Fig. 1) and its recovery was reversely reacted (Fig. 3). Exercise intensity estimated from heart rate was significantly higher in elites $(P=$ 0.0037). In change amount comparison in order to exclude other influential factors between subjects such as ages, heart rate changes did not show significant difference between amateurs and elites (Table 4). The similar pattern of calorie consumption during HR between amateurs and elites did not show significant difference (Fig. 4).

\section{Lactate values and exercise intensity}

Lactate values are higher in amateurs at rest state and lactate of elites continuously increased more than that of amateurs till finished (Fig. 1). We also traced the lactate level in experiment 1 and the results were converse as the lactate was higher in elites at starting point and it subsequently showed reverse response compared to the results in Fig. 1 (data not shown). Compared to recovery rate $30 \mathrm{~min}$ after HR between experiment 1 and 2 (data of experiment 1 not shown), the results were reversely shown even though there is no significant difference. Recovery rate of elites in experiment 1 is shown as about $23 \%$ higher than that of amateurs, however, it was about $23 \%$ higher in amateurs at the 30 min recovery after HR in experiment 2 . We suggest that these results in experiment 2 probably related with the fact (slower and faster response of lactate recovery and lactate expression, respectively) that exercise intensity is significantly higher in elites rather than amateurs shown in Fig. $2(P=0.037)$ (However, we could not measure the exercise intensity resulted from heart rate in experiment 1). We strongly suggest that this reverse data between experiment 1 and experiment 2 comes from others factor such as age differences between elites and amateurs in each experiment (Table 1). For the aspect of inflammatory and oxidative stress dependent intensity of exercise (Azizbeigi et al., 2015), we suggested the different metabolic responses caused in elites and amateurs in different experiments. Lactate increases in mechanical overload to induce oxidation in heart and slow fiber by transporting monocarboxylate transporter (MCT) 1 and MCT4, which stimulates as a cascade of muscle hypertrophy regulation even though it was initially considered as a metabolic waste and a fatigue causing substance (Bonen, 2000; Bonen et al., 2000; Gladden, 2004; Kitaoka et al., 2011). It can be suggested that lactate is recognized as a signal medium involving protein anabolic mechanism to muscle hypertrophy (Enoki et al., 2006). In experiment 2, we possibly speculate that lactate in elites is continuously produced to efficiently accelerate the metabolic systems rather than ama- teurs (Fig. 3).

\section{Physical fitness measurement in amateurs and elites}

Generally, elites have better physical functions of test parameters (Table 2). It suggests that HR causes effective physical fitness ranging over various aspects, such as not only muscle strength, muscle mass, cardiorespiratory endurances, agility, but also balance. These results reflect the characteristics obtainable by HR: Holding reins with erected posture on the horse strengthens hand muscles, back muscles, and the sense of balance to have control over horses for Show Jumping game.

\section{Changes of body compositions, heart rate and calorie consumption during Show Jumping}

We examined body compositions, heart rate, calorie consumption before, on the way of riding, and after the riding of Show Jumping. Compared to the subjects of experiment 1 showed in table 1 , those of experiments 2 and 3 have substantially different age ranges of subjects (Table 1). Thus, we used each values calculated from Formula 1 described in Materials and Methods to compare only increment before and after HR and to eliminate the possibility causing the effect of age difference (Tables 3, 4). It is interesting that subtle body compositional changes such as body weight, body water, muscle mass, and fat were caused by only less than 20 min HR exercise and it suggests that HR during Show Jump is more than moderate to severe exercise (Table 3).

We also could measure heart rate (Table 4) and calorie consumption (Fig. 4) in real time before, during, and after HR. While Rest and Walk, heart rate between amateurs and elites was similar. Higher heart rate was shown by elites compared to amateurs during Jump period. It suggests that skillful elites are involuntarily trained to only focus more at necessarily proper moment to evade failure of the game.

In calorie consumption, elites were consuming less calories during Show Jump. It suggests that elites are more rhythmically harmonized with their horses without unnecessary caloric consumption compared to amateurs. It suggests that those test parameters are not mainly affected to the results of game, but supposedly more affected by skillful control of elites.

\section{Limitations of this study}

Physiological and psychological nature, genetic properties such as individual physique, its condition, etc were not totally controlled. Different subjects in this study were allocated into each experiment. 
In conclusion, we found that long term HR experience possibly improve various physiological changes such as balance capability. During 18 min HR, skeletal muscle mass and body fat were delicately showed its positive changes. In metabolic changes during $\mathrm{HR}$, lactate response was seen more sensitive in elites rather than amateurs and its recovery was reversely reacted. Coincidently, exercise intensity was estimated from heart rate and it was significantly higher in elites $(P=0.037)$. Calorie consumption tested in real time during $\mathrm{HR}$, which has the similar results with the intensity of HR exercise. HR induces physiologically positive effects such as muscle strength, balance, oxidative capability, flexibility, muscle-nerve integrated control capability as well as psychologically positive changes and thus highlighted as combined exercise for women, children, and aged as therapeutic, rehabilitative, and leisure sport activity.

\section{CONFLICT OF INTEREST}

No potential conflict of interest relevant to this article was reported

\section{REFERENCES}

Ainsworth BE, Haskell WL, Leon AS, Jacobs DR Jr, Montoye HJ, Sallis JF, Paffenbarger RS Jr. Compendium of physical activities: classification of energy costs of human physical activities. Med Sci Sports Exerc 1993;25(1):71-80.

Azizbeigi K, Azarbayjani MA, Atashak S, Stannard SR. Effect of moderate and high resistance training intensity on indices of inflammatory and oxidative stress. Research in sports medicine 2015;23(1):73-87.

Bonen A. Lactate transporters (MCT proteins) in heart and skeletal muscles. Med Sci Sports Exerc 2000;32(4):778-789.

Bonen A, Miskovic D, Tonouchi M, Lemieux K, Wilson MC, Marette A, Halestrap AP. Abundance and subcellular distribution of MCT1 and
MCT4 in heart and fast-twitch skeletal muscles. Am J Physiol Endocrinol Metab 2000;278(6):E1067-1077.

Devienne MF, Guezennec CY. Energy expenditure of horse riding. Eur J Appl Physiol 2000;82(5-6):499-503.

Enoki T, Yoshida Y, Lally J, Hatta H, Bonen A. Testosterone increases lactate transport, monocarboxylate transporter (MCT) 1 and MCT4 in rat skeletal muscle. J Physiol 2006;577(1):433-443.

Gladden LB. Lactate metabolism: a new paradigm for the third millennium. J Physiol 2004;558(1):5-30.

Heine B. Hippotherapy. A multisystem approach to the treatment of neuromuscular disorders. Aust J Physiother 1997;43(2):145-149.

Kim SG, Lee JH. The effects of horse riding simulation exercise on muscle activation and limits of stability in the elderly. Arch Gerontol Geriatr 2015;60(1):62-65.

Kitaoka Y, Machida M, Takemasa T, Hatta H. Expression of monocarboxylate transporter (MCT) 1 and MCT4 in overloaded mice plantaris muscle. J Physiol Sci 2011;61(6):467-472.

Lee S, Lee D, Park J. Effects of the indoor horseback riding exercise on electromyographic activity and balance in one-leg standing. J Phys Ther Sci 2014;26(9):1445-1447.

Liptak GS. Complementary and alternative therapies for cerebral palsy. Ment Retard Dev Disabil Res Rev 2005;11(2):156-163.

Murphy D, Kahn-D'Angelo L, Gleason J. The effect of hippotherapy on functional outcomes for children with disabilities: a pilot study. Pediatr Phys Ther 2008;20(3):264-270.

Sherrington C, Lord SR, Finch CF. Physical activity interventions to prevent falls among older people: update of the evidence. J Sci Med Sport 2004;(1):43-451.

Trowbridge EA, Cotterill JV, Crofts CE. The physical demands of riding in National Hunt races. Eur J Appl Physiol Occup Physiol 1995;70(1): 66-69.

Westerling D. A study of physical demands in riding. Eur J Appl Physiol Occup Physiol 1983;50(3):373-382. 